\title{
Successful Treatment of a Critical ill Newborn with COVID-19 Pneumonia after Cesarean Section
}

\author{
Fuyong Jiao ${ }^{1}$, Chongchen Zhou ${ }^{3}$, Yibo Cheng ${ }^{3}$, Shuying Luo ${ }^{3}$, Lei $\mathrm{Ma}^{1}$, Xinggang Zhen ${ }^{3}$, Yingjun \\ Feng ${ }^{3}$, Min Li ${ }^{3}$, Stefan Bittmann ${ }^{2 *}$ \\ ${ }^{1}$ Children's Hospital, Xiatong University, China
}

${ }^{2}$ Department of Pediatrics, Ped Mind Institute, Germany

${ }^{3}$ Henan Provincial Children`s Hospital, Children`s Hospital affiliated to Zhengzhou University, China

*Corresponding author: CStefan Bittmann, Head of the Department of Pediatrics and Ped Mind Institute D-48599 Gronau, Germany.

To Cite This Article: Stefan Bittmann. Successful Treatment of a Critical ill Newborn with COVID-19 Pneumonia after Cesarean Section. 2020 - 9(3). AJBSR.MS.ID.001383. DOI: 10.34297/AJBSR.2020.09.001383.

Received: 製June 08,2020; Published: 㑡 June 25, 2020

\section{Introduction}

We report about a 5 day old newborn with critically pneumonia SARS-CoV-2 after cesarean section infected by a family cluster infection. A male newborn was admitted 22 days after delivery due to "intermittent fever for 17 days". That means that on the fifth day after delivery, due to Cesarean section, the newborn began to fever. In short, history of pregnancy and delivery modus was G1P1, 22 days ago (31 Jan 2020). The newborn was delivered in $38+5$ weeks gestation by c-section. Amniotic fluid, umbilical cord and placenta was normal, APGAR score at 1, 5 and 10 minutes normal. 18 days ago (04 Feb 2020) the child developed fever with a peak of $38.0^{\circ} \mathrm{C}$. The child showed choking cough, had no running nose, no vomiting, no diarrhoea, any convulsions or skin rashes.

17 days ago, on 02 of February 2020, the fever in outpatient clinic in Xinyang Center Hospital processed. A swab test for SARSCoV-2 virus nucleic acid testing was positive. 15 days ago, on 6th of February 2020, fever was present once up to $37.7^{\circ} \mathrm{C} .17$ days before the child see a doctor in the center of the Xinyang Hospital. The medical treatment was based on ribavirin, cephalosporin, immunoglobulin (2.5 g, application 5 days), albumin (3 g, application of 3 days), atomization interferon, Lopinavir/Ritonavir ( $0.5 \mathrm{ml} /$ per time, all $12 \mathrm{~h})$. Under these medications the child had temperature fluctuations with highest temperature of 37.5 ${ }^{\circ} \mathrm{C}$, discontinuous, when administering oxygen inhalation through nasal catheter oxygen intolerance. The child had no failure to thrive, but had choking cough. For further treatment, with a diagnosis of "COVID-19" the newborn was admitted to our hospital from emergency ambulance. In this moment of admittance, the child's mental reaction was poor, but sleep was normal, the newborn showed normal stool and normal urine.
The parents had been living in Wuhan City, before the baby was born. On January 22, the parents of the baby returned to Xinyang City from Wuhan. In the afternoon of that day, the mother felt cold and drowsy. The father and grandfather of the child were diagnosed with COVID-19 on April 4th. The baby's grandmother was diagnosed on February 25. Physical examination showed full month appearance, weight of $3600 \mathrm{~g}$, body temperature was $36.5^{\circ} \mathrm{C}$, pulse rate 172 times/min, respiration rate of 40 times/min. The blood pressure was initially measured by $74 / 36 \mathrm{~mm} \mathrm{Hg}$, height was $51 \mathrm{~cm}$. There was no malformation in the skull, the anterior fontanelle was $2.5 \mathrm{~cm} \times 2.5 \mathrm{~cm}$, the posterior fontanelle was closed, flat and soft, and the tension was normal. Bilateral pupil showed isocorie, the reflex to light existed. The breath was smooth under oxygen inhalation by nasal catheter was performed. No expiratory dyspnoea was found. The three concave signs were negative.

The breath sounds in both lungs were rough. Heart rhythm was uniform, heart sounds were strong, no murmur was heard, abdomen was soft, umbilical cord did not fall off, liver reached $1.5 \mathrm{~cm}$ below right costal, soft, spleen was not reached, bowel sounds were normal. The extremities were warm at the end, with free movement, normal muscle tone, and primitive reflexes. Laboratory blood routine examination showed leukocyte $12.95 \times$ $109 / \mathrm{L}$, erythrocyte $3.07 \times 1012 / \mathrm{L}$, hemoglobin $101 \mathrm{~g} / \mathrm{L}$, platelet $356 \times 109 / \mathrm{L}$, lymphocyte percentage $49.5 \%$, c-reactive protein quantitative determination $<0.5 \mathrm{mg} / \mathrm{L}$. Liver and kidney function, myocardial enzymes, electrolytes: total bilirubin $13.7 \mathrm{umol} / \mathrm{L}$, conjugated bilirubin 2.7 umol/L, unconjugated bilirubin 11.0 umol/L, alanine transaminase $46.7 \mathrm{U} / \mathrm{L}$, glutamate transaminase $37.8 \mathrm{U} / \mathrm{L}$, creatine kinase isoenzyme $48.3 \mathrm{U} / \mathrm{L}$, potassium 6.75 mmol/L (Figure 1). 
Computer tomography showed local thickening of double lung texture, small patch density increased shadows. A fuzzy edge was found. Chest CT reviewed on March 1 showed, that the lung film was more clearly absorbed than before. After admission, the child was placed in the isolation ward for treatment and have been given a warm box insulation. The newborn had nasal catheter application of oxygen, interferon injection by oral cavity and ambroxole at the same time. The heart rate was closely monitored. Respiration, blood pressure, electrolyte were also closely monitored. Furosemide was given as diuretic, cefoperazone was given. Sedation, heart strengthening, diuretic, fluid limitation, circulation improvements were initiated. IN the next days, the child's body temperature was normal, no cough, no dyspnea, good nursing, normal defecation and urination. Further two time nucleic acid tests were negative and the condition of the newborn was significantly improved. They were followed up for two weeks after discharge. Finally, the baby recovered normal, and the spirit and aspect was finally very good. No rise of temperature of fever was found in course.

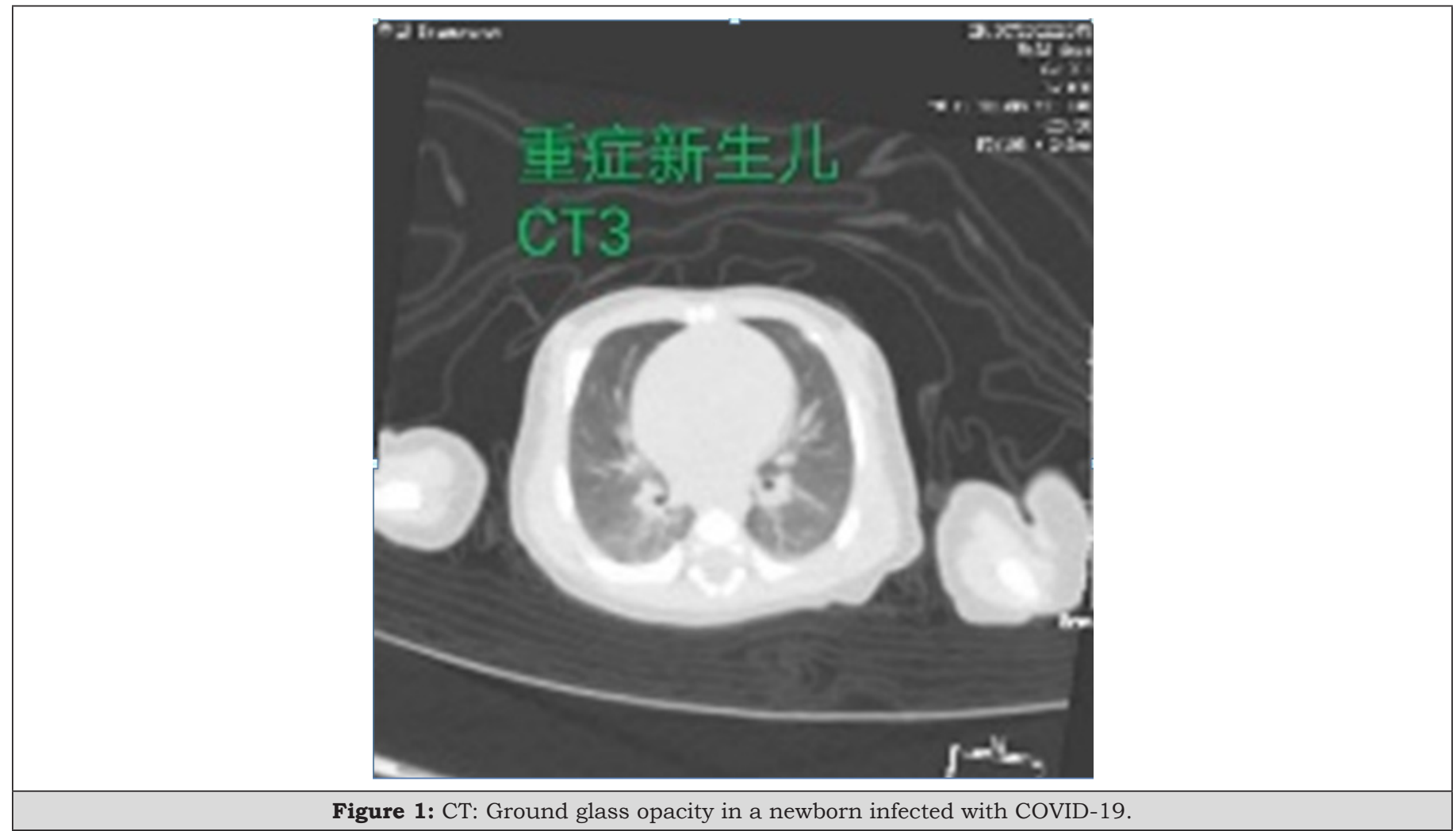

In conclusion, because of the family gathering, the clinical diagnosis and treatment characteristics of a new coronary pneumonia combined with psychological exhaustion caused by non-mother-to-child transmission after cesarean section were analyzed. It is a description of a case of neonatal severe coronavirus pneumonia 5 days after cesarean section in Children's Hospital affiliated to Zhengzhou University. As a result the neonate lived for 5 days with febrile COVID-19 infection. However, the children turned into micro-severe, coronavirus pneumonia, combined with psychological failure, after rescue treatment, accounting and testing twice negative at discharge. Cesarean section and family members infection easy caused neonatal critical pneumonia, and this should strengthen the diagnosis and treatment. This case shows impressingly the course of a COVID-19 infected neonate due to cluster infection of the whole family. 